\title{
ANÁLISE DE FALHA DE ENGRENAGENS DE REDUTORES GRANDE PORTE*
}

Larissa Mitie Ihara ${ }^{1}$ Deniol Katsuki Tanaka²

\section{Resumo}

Foram encontrados vários casos de falha de engrenagens de redutores de grande porte, aplicados em turbogeradores em usinas de cogeração. Este trabalho tem como objetivo a análise de falha dessas engrenagens bihelicoidais. Engrenagens operam sob condição de carregamento cíclico variável, logo seus principais modos de falha são fadiga de contato e por flexão de dentes. A engrenagem estudada, fabricada em aço 18CrNiMo7-6, foi utlizada em campo e apresentou fratura em dois dentes. Realizou-se uma análise de espectrofotometria para confirmação da composição química do material base. Uma análise microestrutural foi realizada utilizando microscopia óptica, revelando que a microestrutura corresponde a martensita com austenita retida. Foi feito um perfil de microdureza no plano transversal do dente, que indicou uma camada cementada efetiva de $2.150 \mu \mathrm{m}$ e dureza de $715 \mathrm{HV}_{0.1}$ na superficie. Foi feita uma fractografia macroscópica para determinação das caracteristicas da fratura, o que permitiu identificar marcas de praia e deltas de rio. Aliado a isso, foram feitas imagens por microscopia eletrônica de varredura, determinando o local do início da trinca. A partir dessas evidências, pôde-se concluir que o mecanismo de falha predominante foi fadiga por flexão de dente.

Palavras-chave: Análise de falha; Engrenagens; Fractografia; Fadiga.

\section{FAILURE ANALYSIS OF GEARS OF LARGE TRANSMISSION SYSTEMS Abstract}

Several cases of gear failure occurred in large transmission systems, applied to turbogenerators in cogeneration power plants. This work aims to do the failure analysis of the material of these double helical gears. Gears operate under variable cyclic stress, hence the main modes of failure are contact and bending fatigue. The studied gear, manufactured in 18CrNiMo7-6 steel, worked on the field and presented fracture of two teeth. An analysis of spectrophotometry confirmed the chemical composition of the base material. A microstructural analysis was conducted by means of an optical microscope, which revealed that the microstructure corresponds to martensite and retained austenite. A microhardness profile was completed, which denoted an effective carburised layer of $2,150 \mu \mathrm{m}$ and hardness of $715 \mathrm{HV}_{0.1}$ on the surface. A macroscopical fractography was done, in order to determine features of the fracture, which allowed for identification of beach marks and river deltas. In addition, imaging by scanning electron microscopy determined the crack iniation site. Based on this evidence, it could be concluded that the predominant failure mechanism was tooth bending fatigue.

Keywords: Failure analysis; Gears; Fractography; Fatigue.

1 Engenharia Mecânica, Engenheira Mecânica, Mestranda em Engenharia Mecânica, Departamento de Engenharia Mecânica, Escola Politécnica da Universidade de São Paulo, São Paulo, SP, Brasil.

2 Engenharia Mecânica, Doutor em Engenharia Metalúrgica, Professor Titular, Departamento de Engenharia Mecânica, Escola Politécnica da Universidade de São Paulo, São Paulo, SP, Brasil. 


\section{INTRODUÇÃO}

Nos dentes de engrenagens, a análise das tensões é feita considerando o dente como uma curta viga engastada, que sofre flexão devido ao contato entre os dentes engrenados. Por conta desse carregamento e da rotação das engrenagens, a tensão gerada dentro dos dentes é composta conforme ilustrado na Figura 1.

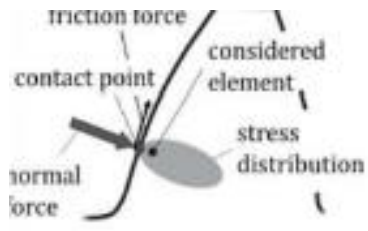

a)

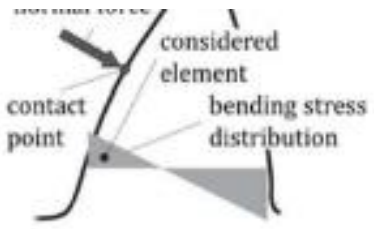

b)

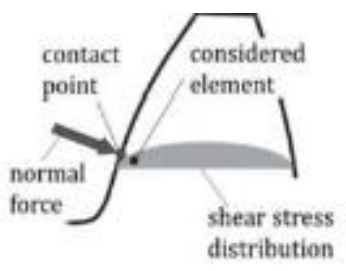

c)

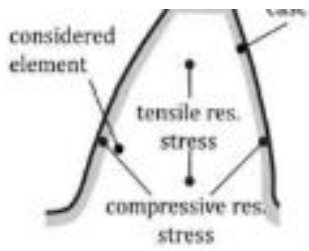

d)

Figura 1. Estado de tensões dentro do dente. [1]

A Figura 1a mostra a distribuição da tensão de contato devido à força normal resultante da transmissão de torque. A Figura 1b ilustra a distribuição aproximadamente linear da tensão de flexão ao longo da seção transversal do dente, resultante de um momento fletor devido ao carregamento. A Figura 1c representa a componente cisalhante da tensão na superfície do flanco, que também se deve à força normal de contato. A Figura $1 \mathrm{~d}$ apresenta as tensões residuais, que podem advir de tratamentos superficiais que induzem tensões compressivas na superfície, internamente compensadas por tensões trativas no núcleo. As tensões residuais não dependem do carregamento e, enquanto não houver deformação plástica significativa na superfície, mantêm-se constantes no tempo. [1]

Engrenagens operam sob condição de carregamento cíclico variável, portanto estão sujeitas a dano acumulativo por fadiga. Além do mais, devido ao contato entre os dentes, o desgaste também pode-se tornar um risco de falha. Em engrenagens helicoidais, as linhas de contato não são paralelas aos eixos das engrenagens, gerando uma distribuição não-uniforme do carregamento, devido à variação da rigidez do dente ao longo dessas linhas de contato.

Este Estudo tem como objetivo a análise de falha de engrenagens bihelicoidais e foi motivado por casos de falha encontrados por um fabricante de redutores de grande porte, aplicados em turbogeradores em usinas de cogeração - 6,6\% dos redutores fabricados nos anos de 2002 a 2014 apresentaram quebra de dente. Segundo Yang et al. [2], $60 \%$ das falhas nos sistemas de transmissão devem-se às engrenagens, 0 que incorre em paradas (downtime) e reposição de componentes danificados, ocasionando prejuízos econômicos e operacionais.

\subsection{Definição do problema}

O estudo de caso da análise de falha apresentado neste trabalho consiste em uma engrenagem bihelicoidal de um redutor, que transmite a potência entre uma turbina a vapor de 50 MW e um gerador elétrico. O redutor foi fabricado em 2009; em 2013, ocorreu uma primeira falha da engrenagem, que foi substituída, mas falhou novamente um ano depois. A engrenagem estudada é a coroa do conjunto (114 dentes com relação de transmissão de 2,78) e apresentou fratura parcial de dois dentes não-consecutivos, no lado do centro, i.e., próximo ao gap da engrenagem bihelicoidal. 


\section{MATERIAIS E MÉTODOS}

Os seguintes métodos de análise foram utilizados no desenvolvimento desse trabalho:

- Espectrofotometria para análise de composição química

- Microscópio óptico Olympus modelo BX60M para metalografia

- Microdurômetro Vickers (100 gf) fabricado pela Buehler

- Perfilômetro óptico 3D sem contato modelo CCI MP da Taylor Hobson (software Talysurf e Talymap) para medição da topografia

- Câmera digital Nikon D5100 com lente Nikon AF-S DX Nikkor 18-105mm f/3.5-5.6G ED VR, estereomicroscópio Nikon modelo SMZ800 (câmera digital Nikon 1200F, software ECT-1), e microscópio eletrônico de varredura (MEV) marca FEI modelo Inspect F50 para fractografia

\section{RESULTADOS E DISCUSSÃO}

As amostras foram caracterizadas e suas superfícies de fratura foram minuciosamente estudadas, a fim de determinar o modo de falha, o início da trinca e seu mecanismo de propagação.

Realizou-se uma análise de espectrofotometria, que confirmou a composição química do material base (aço 18CrNiMo7-6) conforme a especificação. A micrografia revelou uma morfologia martensítica com uma fração de austenita retida não determinada, como pode se observar na Figura 2 (feita no microscópio óptico). Foi identificada uma baixa frequência de inclusões (setas), observando-se uma geometria esférica das mesmas tornando-as pouco propicias como local de nucleação de trincas.

(a)

(b)

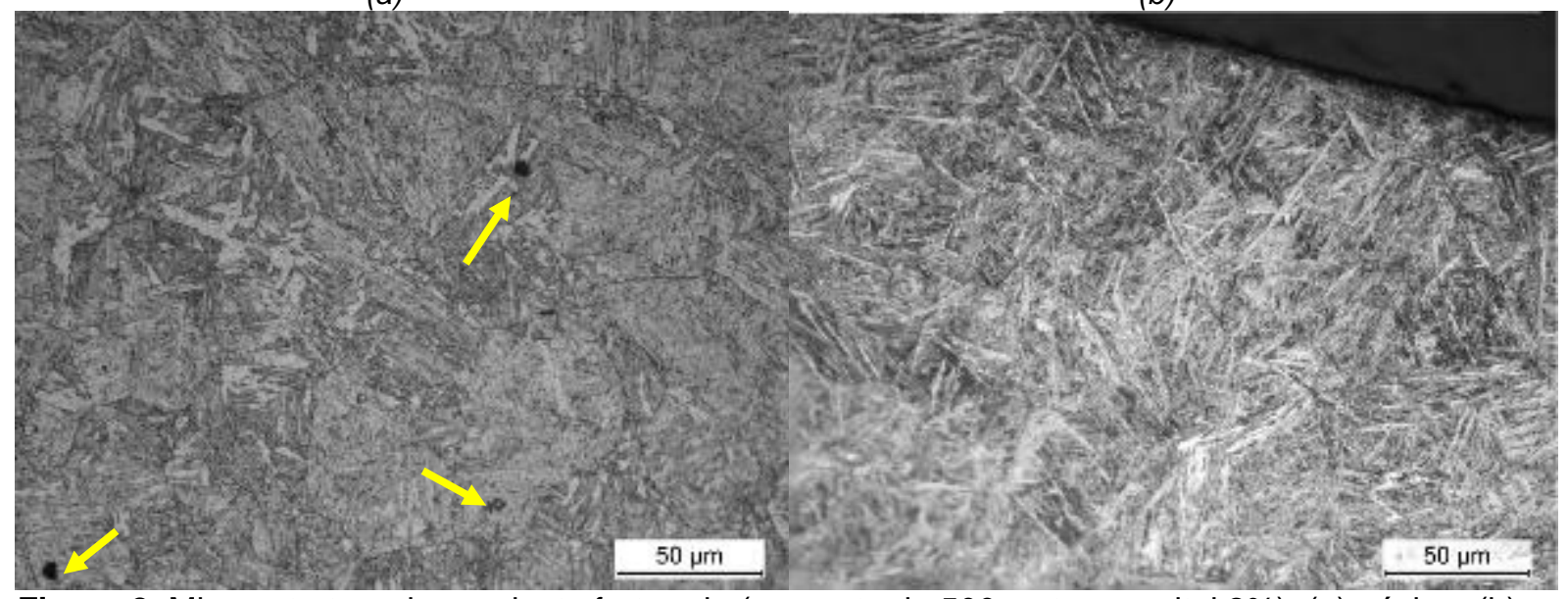

Figura 2. Microestrutura de um dente fraturado (aumento de 500x, ataque: nital 2\%): (a) núcleo, (b) camada cementada. Fonte: elaborado pela autora.

Visto que os dentes da engrenagem são cementados, mediu-se o perfil de microdureza Vickers no plano transversal do dente (Figura 3), a partir do qual se observou a camada efetiva com $2.150 \mu \mathrm{m}$ (onde a dureza é de $550 \mathrm{HV}$, segundo a Norma ISO 2639) e dureza de aproximadamente $715 \mathrm{HV}_{0,1}$ na superfície. A especificação de projeto era 1,2 - 1,4 mm de espessura. 


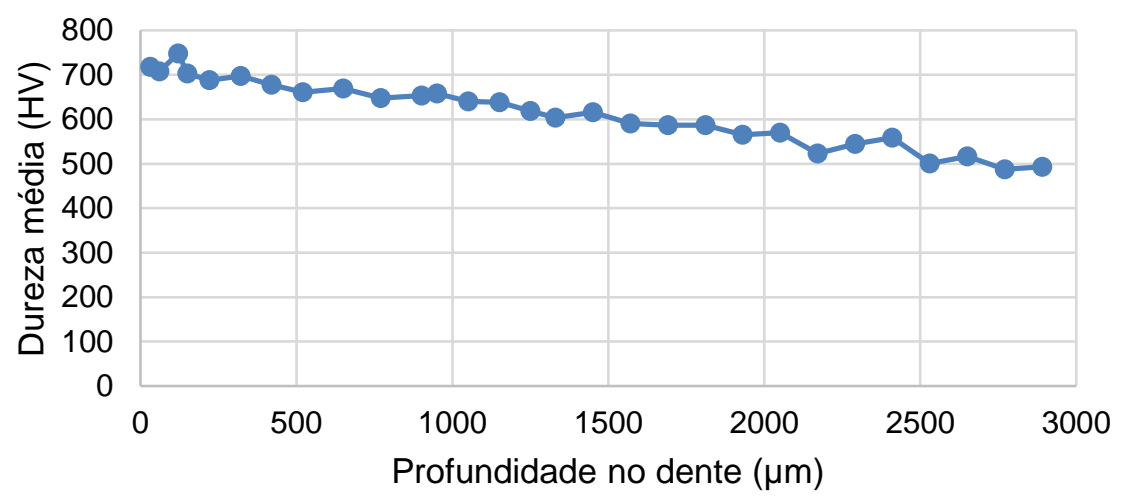

Figura 3. Perfil de microdureza da amostra (carga: $100 \mathrm{gf})$.

A camada cementada também foi observada por meio de uma macrografia, como visto na Figura 4 . $\mathrm{O}$ reagente usado foi $\mathrm{HCl} 30 \%$ a $70 \stackrel{\circ}{ } \mathrm{C}$, ataque por 30 minutos. $\mathrm{O}$ traço vermelho marca aproximadamente a profundidade de $2 \mathrm{~mm}$.

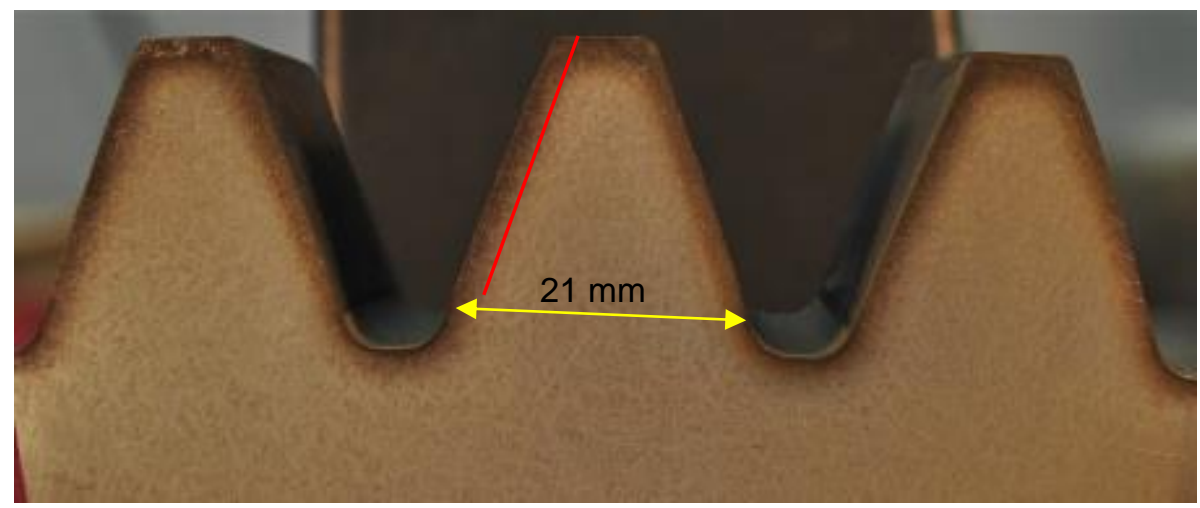

Figura 4. Macrografia de dentes da engrenagem. Fonte: elaborado pela autora.

No perfilômetro óptico 3D sem contato (CCI), foi medida a rugosidade superficial do dente tanto no flanco não carregado (referência), quanto no flanco ativo, onde já ocorreu desgaste - vide Figura 5. A média das medições rendeu os seguintes valores: $S_{a}=0,4999$ no flanco não carregado (quatro medições) e $S_{a}=0,4487$ (duas medições na região do contato). Os valores obtidos mostram que o desgaste moderado no flanco de dentes de engrenagens causa um pós-polimento da superfície, o que é comum observar em engrenagens, segundo Flodin e Andersson [3].

A Figura 5 traz também o espectro polar das direções da rugosidade. Nota-se que o desgaste rotacionou a direção principal da topografia - de $88^{\circ}$ (1\% de isotropia) na superfície de referência para $168^{\circ}$ (15\% de isotropia) na superfície de contato onde ocorreu desgaste. 


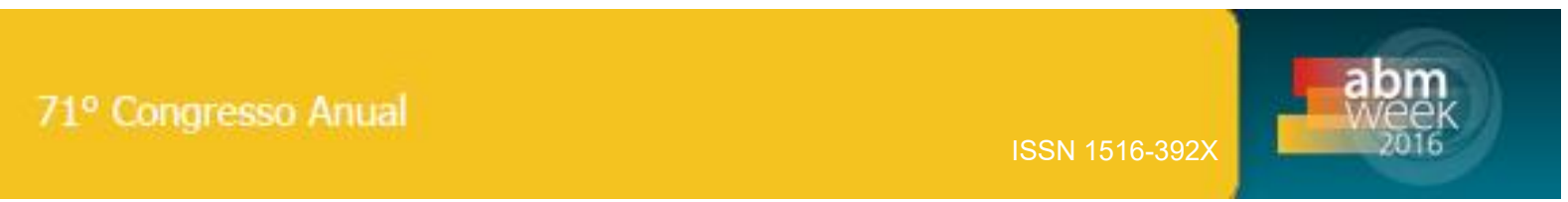

(a)
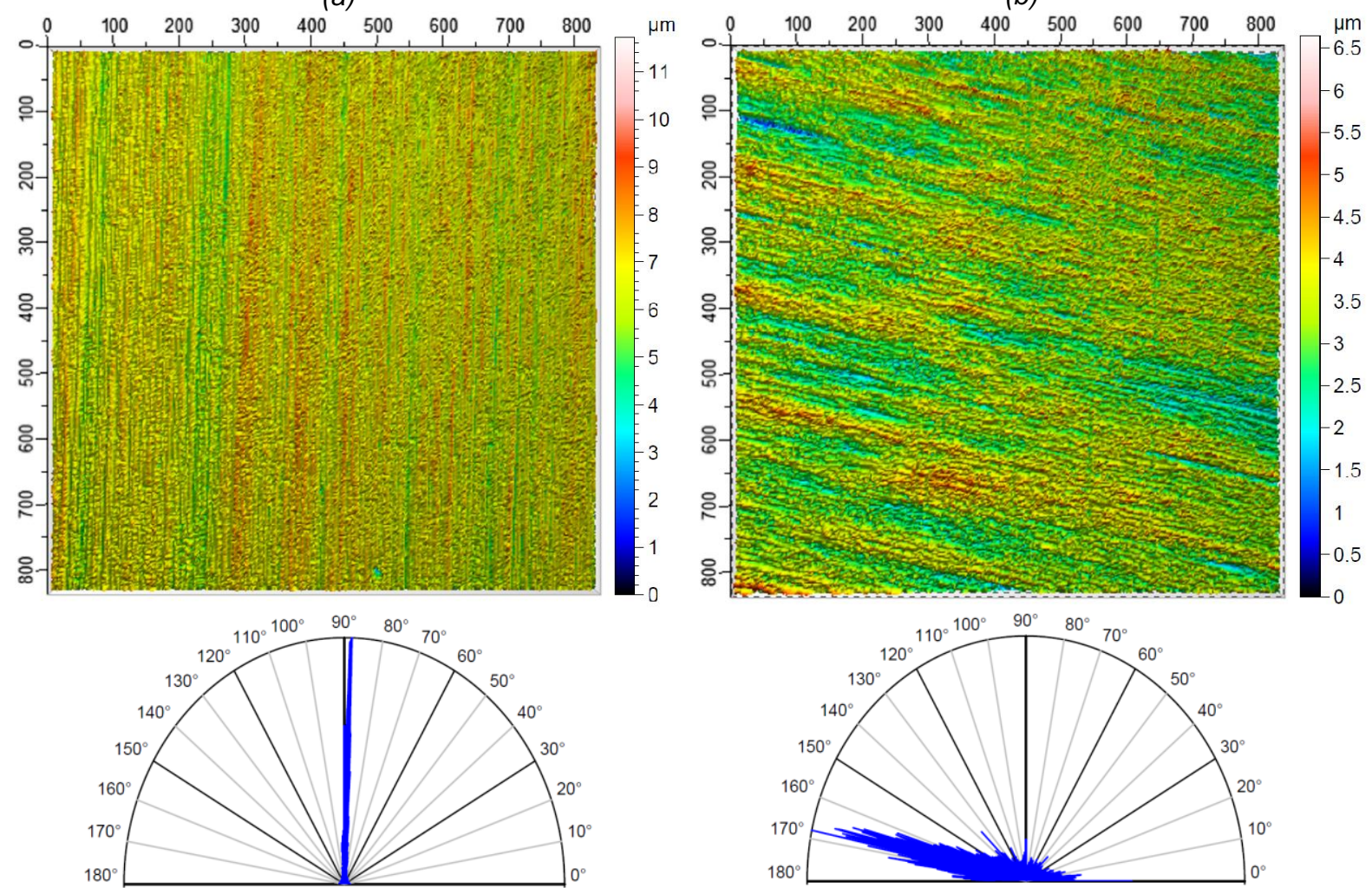

Figura 5. Topografia do dente de engrenagem: (a) flanco não carregado, (b) flanco ativo na região do contato. Fonte: elaborado pela autora.

A Figura 6, feita com lupa portátil Dino-Lite AM4113/ AD4113 Digital Microscope, mostra o flanco de trabalho, próximo ao topo do dente, no centro da engrenagem (início do contato). A Figura ilustra as direções medidas no CCI. A direção de $88^{\circ}$ corresponde à orientação das marcas de retífica (destacado em vermelho na Figura 6). Aproximadamente perpendicularmente, estão orientadas as marcas de desgaste (em amarelo na Figura 6), que se deve ao escorregamento entre os dentes.

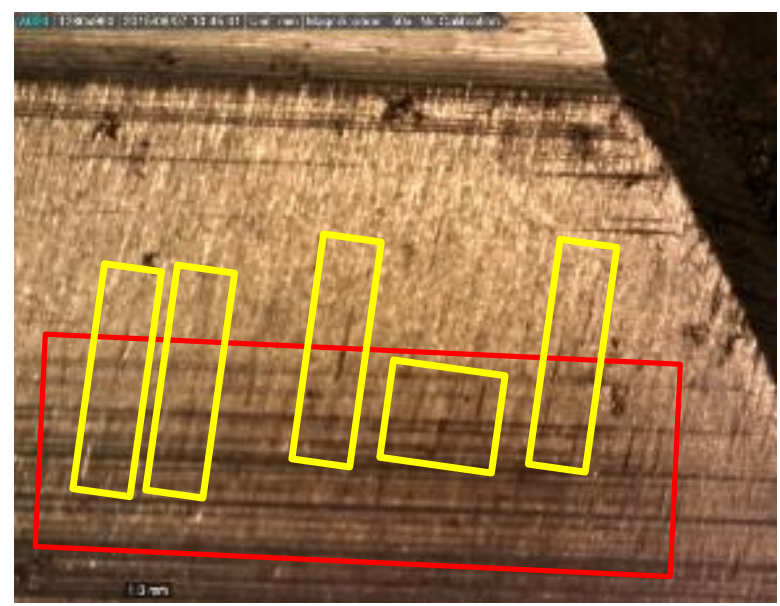

Figura 6. Evidência visual de desgaste no flanco de trabalho, superfície de contato. Aumento de 50x. Fonte: elaborado pela autora.

Seguindo a metodologia recomendada por Vander Voort [4] para identificação da causa de falha, após a caracterização da amostra, deve-se realizar uma análise da fractografia. A análise consiste em uma investigação visual macroscópica da superfície de fratura, acompanhada de registro detalhado por fotografias e esquemas. 
Dois dentes quebraram parcialmente: as Figuras Figura 7 e Figura 8 mostram as fraturas dos dentes aqui denominados \#1 e \#2, respectivamente. A superfície de fratura do dente \#1 estende-se por aproximadamente $100 \mathrm{~mm}$ (largura de base do dente: $197 \mathrm{~mm}$ ), enquanto a fratura do dente \#2 estende-se por aproximadamente 70 $\mathrm{mm}$.

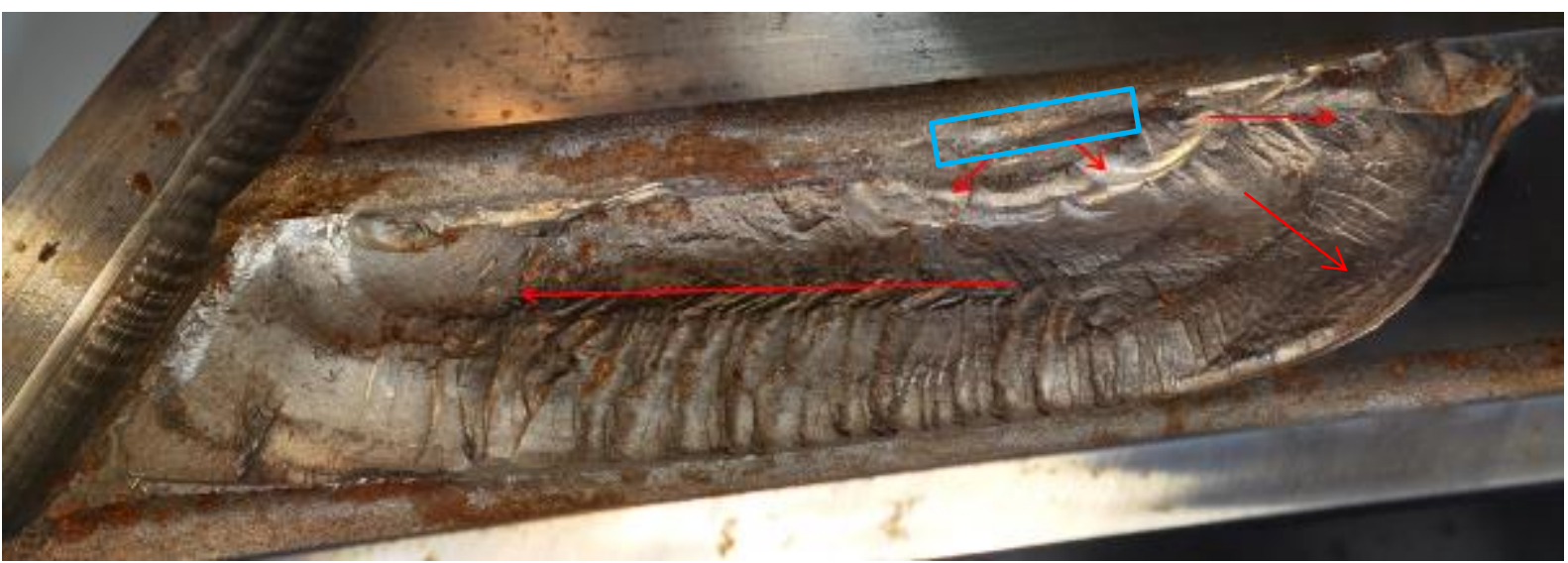

Figura 7. Superfície de fratura do dente \#1. Fonte: elaborado pela autora.

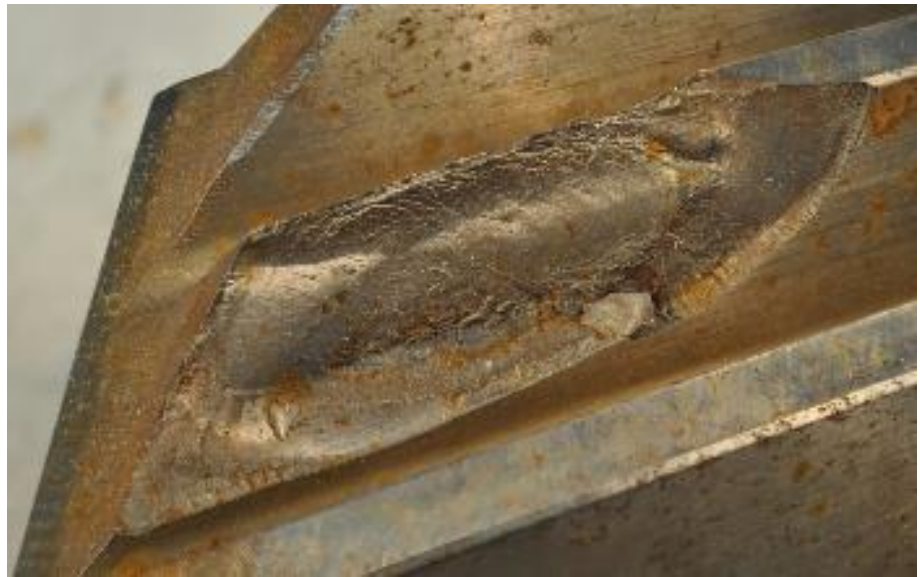

Figura 8. Superfície de fratura do dente \#2. Fonte: elaborado pela autora.

A aparência mais lisa e o menor comprimento da superfície de fratura do dente \#2 indicam que essa ocorreu após a fratura do dente \#1, de maneira que este suportou a propagação da trinca por mais tempo. A sobrecarga ocasionada pela primeira fratura levou então à fratura do dente \#2. Portanto, concentrou-se a análise no dente \#1.

As marcas de desgaste observadas no flanco de trabalho (Figura 9) - reta ao longo do topo do dente, além de uma marca mais escura em apenas um lado dos dentes (próximo ao gap da bihelicoidal) - sugerem um desalinhamento no contato. Essa hipótese também é corroborada pelo fato de o dente não fraturar por inteiro, apenas em um extremo. Os dados coletados e fornecidos pelo fabricante mostram que a maioria das fraturas nas outras engrenagens ocorreu em apenas um extremo do dente, justamente próximo ao gap, por onde se inicia o contato. 

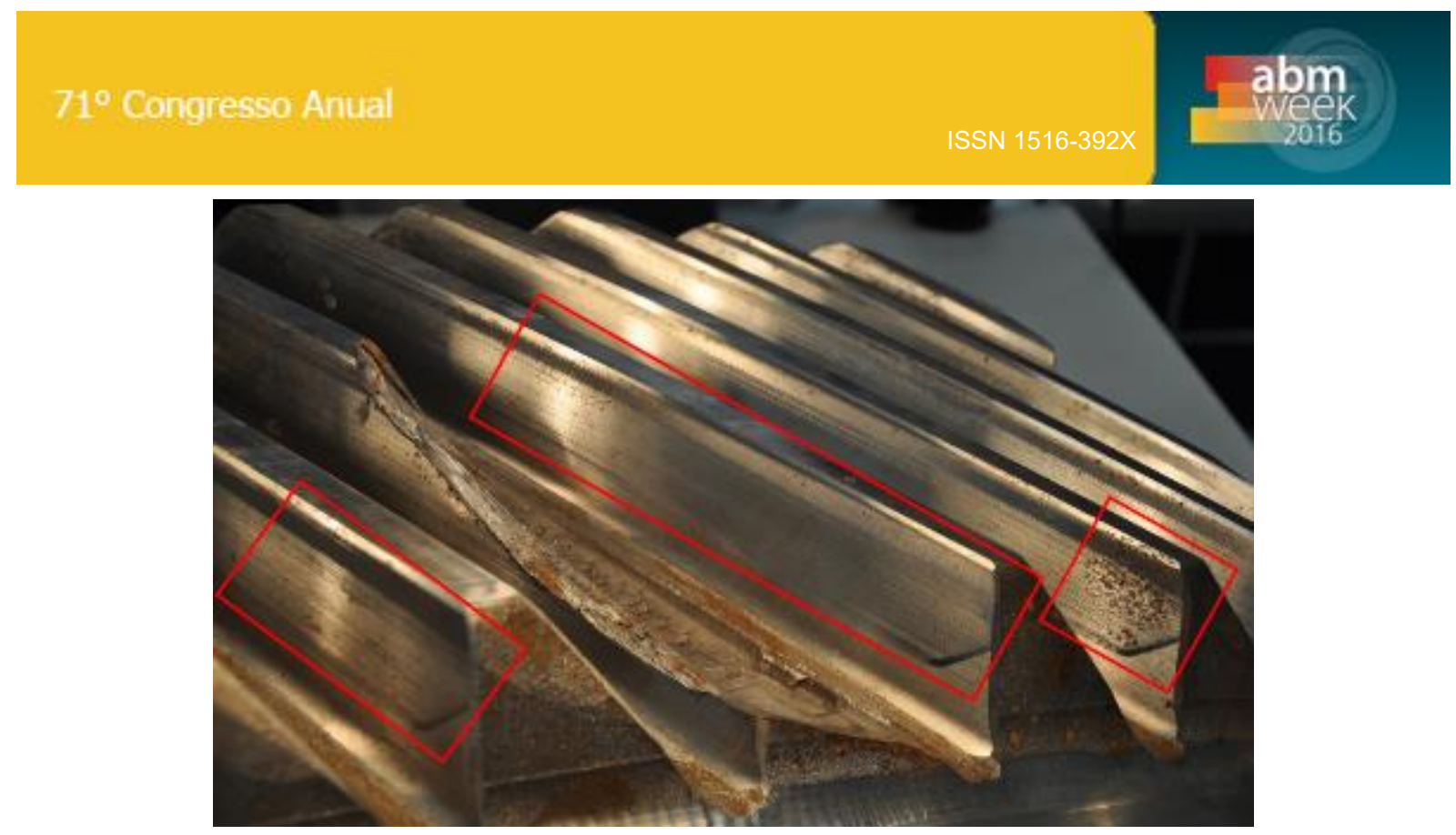

Figura 9. Flanco de trabalho dos dentes. Marcas de desgaste em destaque. Fonte: elaborado pela autora.

As setas na Figura 7 indicam o sentido de propagação da trinca, evidenciado pelas marcas de praia (onde estão as setas menores), os planos de clivagem (seta maior à esquerda) e os deltas de rio (setas médias à direita). A área de aparência lisa mais à esquerda da superfície de fratura indica a fratura final. Portanto, em azul está destacada a região onde deve encontrar-se o início da trinca que levou à fratura.

Marcas de praia seguidas de fratura final com aparência frágil são típicas de falha por fadiga. $\mathrm{O}$ caminho da trinca entra no dente, formando aproximadamente um $\mathrm{L}$, devido à distribuição da tensão de flexão (Figura 1b), descrito por Fernandes [5].

A Figura 10 mostra a região do início da trinca em maior detalhe - foi adicionada uma grade para auxílio, referenciada por Linha (de cima para baixo) x Coluna (da esquerda para a direita). A imagem foi feita no estereomicroscópio com aumento de 10 vezes. Nos quadrados $2 \times 3$ a 2x8, observam-se deltas de rio, indicando que o início da trinca está acima. De $3 \times 14$ a 3×16, notam-se marcas radiais apontando o início da trinca à esquerda.

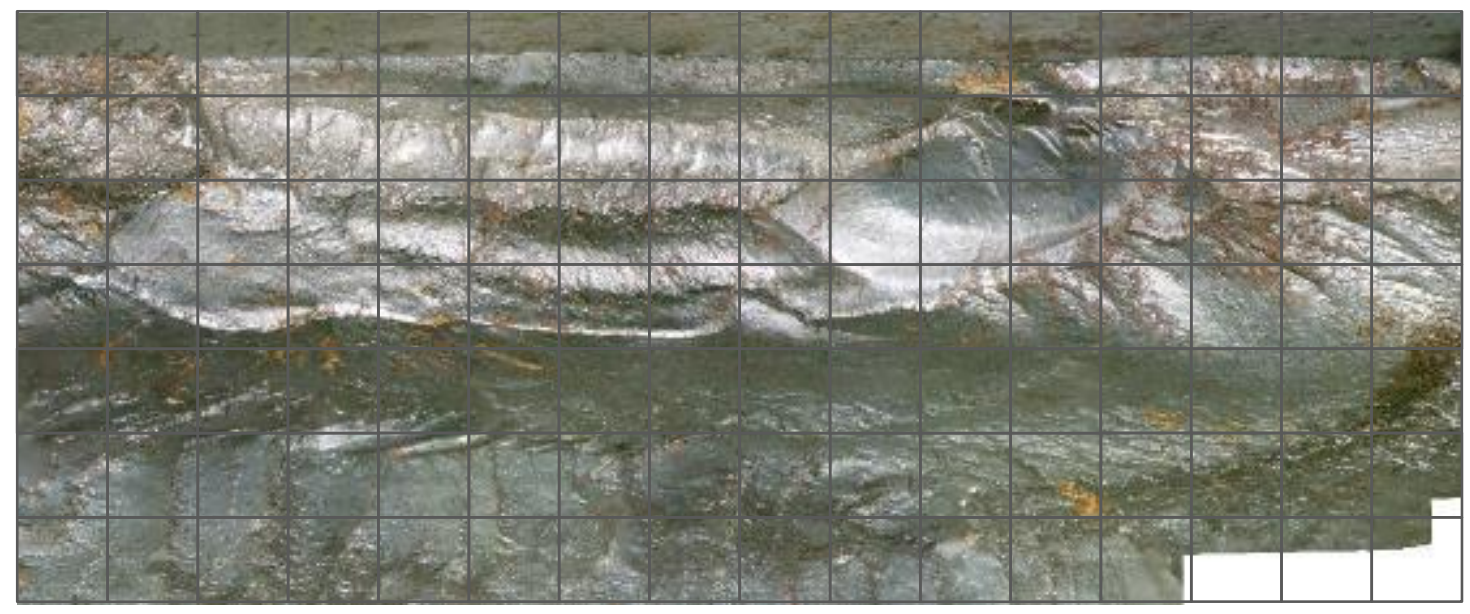

Figura 10. Imagem da região do início da trinca (aumento de 10 vezes). Fonte: elaborado pela autora. 
A região do início da trinca foi então analisada com auxílio do MEV. Foram obtidas as imagens a seguir. A título de localização: 0 delta de rio visto à direita na Figura 11 é 0 mesmo visto no quadrado $2 \times 4$ na Figura 10.

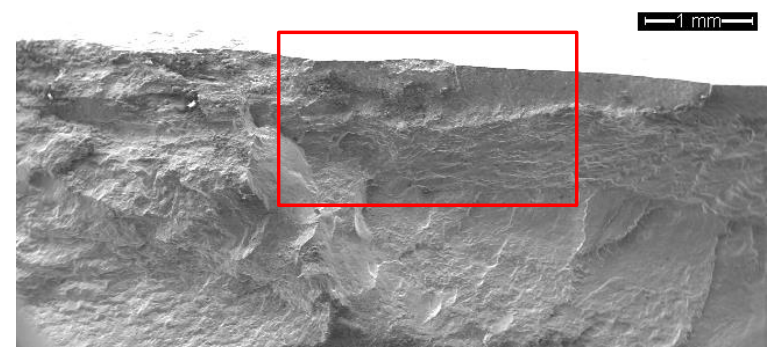

Figura 11. Região do início da trinca. Fonte: elaborado pela autora.

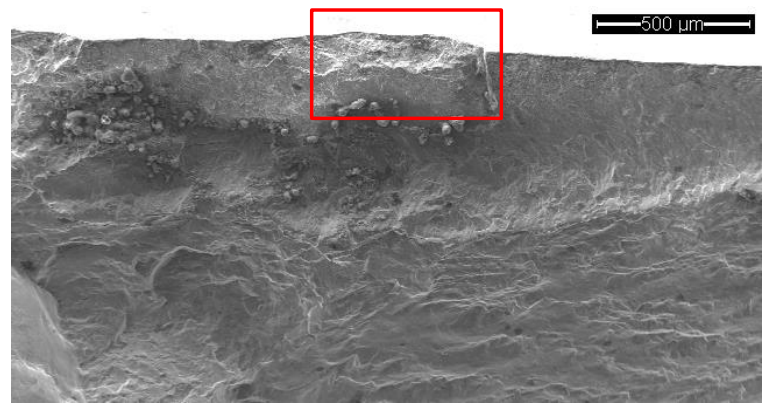

Figura 12. Região do início da trinca (em vermelho na Figura 11). Fonte: elaborado pela autora.

Na superfície, no centro da Figura 11, identifica-se o início da trinca, que se localiza no quadrado $1 \times 3$ na Figura 10. Não foram observadas estrias de fadiga, mas isso pode ser explicado pela baixa ductilidade desse aço (alta dureza) [6] ou também pelo aumento máximo obtido nesse MEV não ser suficiente.

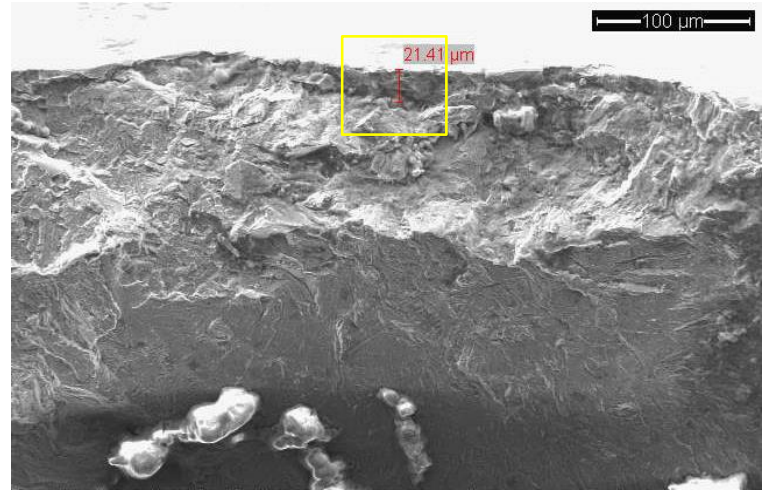

Figura 13. Início da trinca visto (em vermelho na Erro! Fonte de referência não

encontrada.). Fonte: elaborado pela autora.

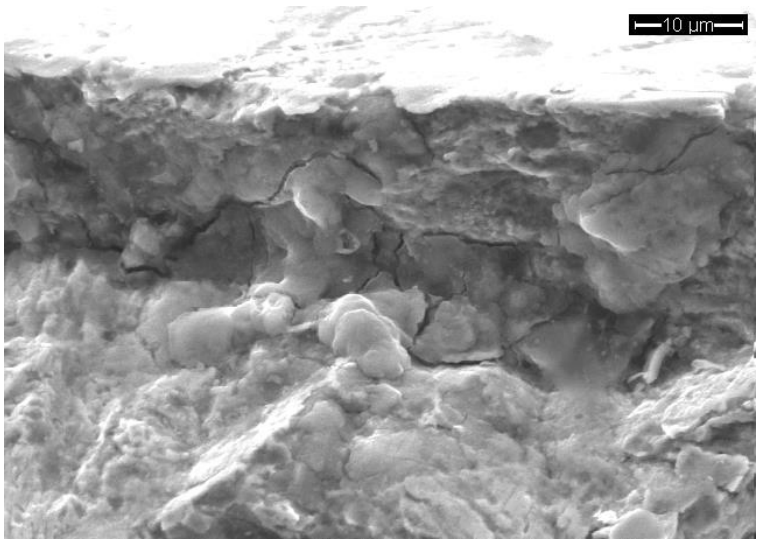

Figura 14. Microtrincas na região do início da trinca que levou à falha. Fonte: elaborado pela autora.

Na Figura 14 (área em amarelo na Figura 13), observam-se algumas microtrincas na região do início da trinca que levou à falha. Nota-se ainda que a trinca tem aparência intergranular no início (destacado em vermelho na Figura 13).

A amostra foi subsequentemente cortada, retificada e polida (abrasivo de $1 \mu \mathrm{m}$ ), de maneira que possibilitasse enxergar o início da trinca na superfície transversal à fratura, que foi registrada no microscópio óptico - vide Figura 15.

Nessa imagem, é possível determinar o caminho percorrido pela trinca em seu início. Além disso, nota-se que trincas secundárias (destacadas em vermelho) formam-se nos entalhes formados pela própria trinca, que agem também como concentradores de tensão, corroborando que a trinca propagou-se por fadiga. 


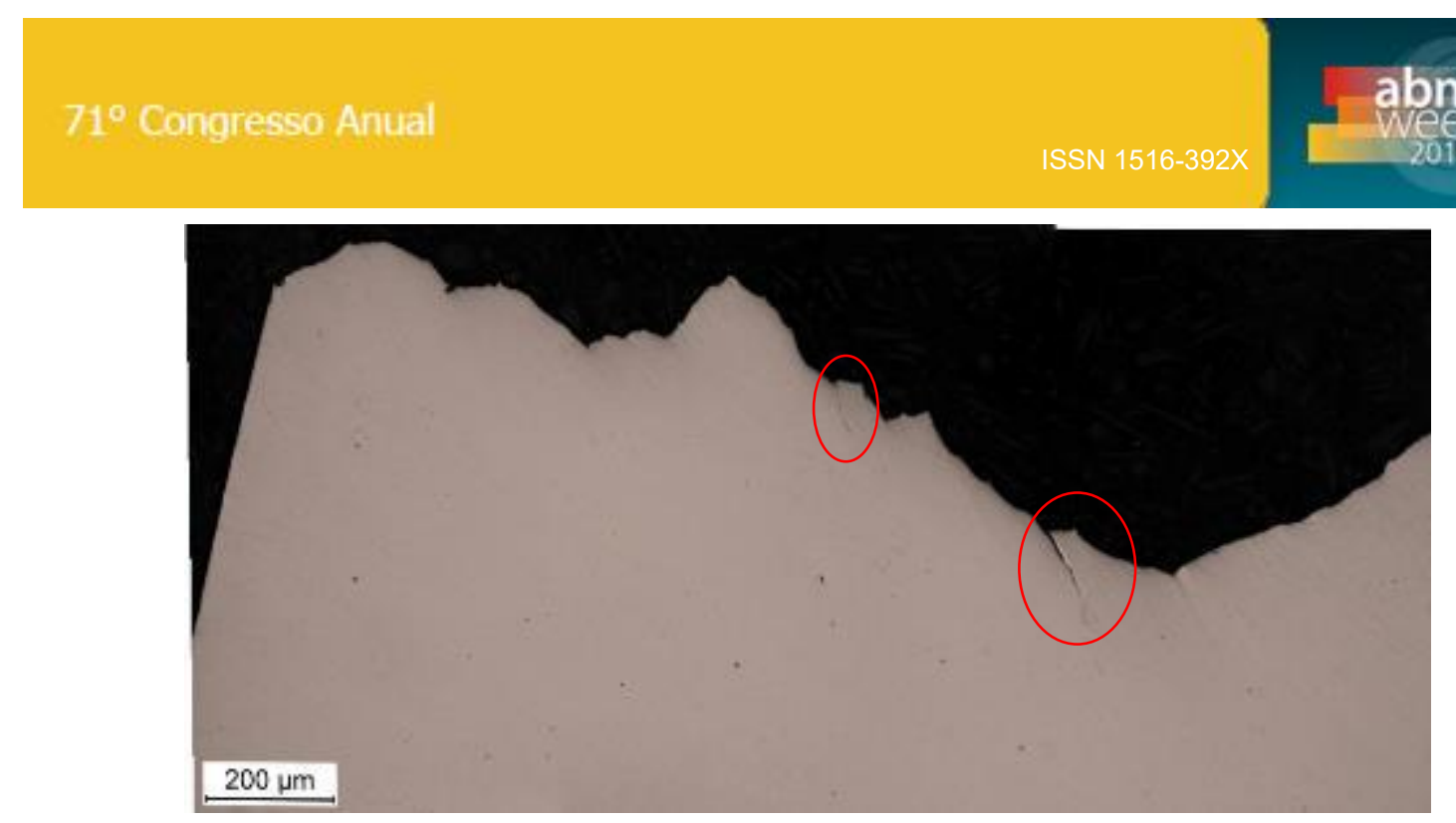

Figura 15. Plano transversal à superfície de fratura, início da trinca (aumento de 100x). Fonte: elaborado pela autora.

\section{CONCLUSÃO}

Esse trabalho mostrou a análise de falha dos dentes de uma engrenagem bihelicoidal do redutor de um turbogerador de grande porte. Foi feita sua caracterização detalhada e nenhuma anormalidade foi detectada. As evidências fractográficas determinaram que a falha ocorreu por fadiga por flexão de dente.

A fadiga por flexão, em tese, advém de um tipo de carregamento que deveria ser levado em consideração e resolvido no projeto. Dessa forma, qualquer fragilidade introduzida no projeto, em combinação com alguma variabilidade na fabricação, pode induzir uma falha prematura. À vista disso, conclui-se que é preciso reavaliar em detalhe todas as tensões envolvidas no funcionamento da engrenagem, a fim de determinar as condições que levaram à falha e sugerir uma solução para aumentar sua confiabilidade.

\section{Agradecimentos}

Os autores gostariam de agradecer à Coordenação de Aperfeiçoamento de Pessoal de Nível Superior pelo apoio financeiro.

\section{REFERÊNCIAS}

1 Boiadjiev, I, Witzig, J, Tobie, T, Stahl, K. Tooth Flank Fracture - Basic Principles and Calculation Model for a Sub-Surface-Initiated Fatigue Failure Mode of Case-Hardened Gears. Gear Technology. 2015; Agosto: 58-64.

2 Yang, D, Liu, Y, Li, S, Li, X, Ma, L. Gear fault diagnosis based on support vector machine optimized by artificial bee colony algorithm. Mechanism and Machine Theory. 2015; 90: 219-229.

3 Flodin, A, Andersson, S. A simplified model for wear prediction in helical gears. Wear. 2011; 249: 285-292.

4 Vander Voort, GF. Macroscopic examination procedures for failure analysis. In: McCall, JL, French, PM. Metallography in failure analysis. New York: Plenum Press, 1978.

5 Fernandes, PJ. Tooth bending fatigue failures in gears. Engineering Failure Analysis. 1996; 3(3): 219-225.

6 Dieter, GE. Mechanical Metallurgy. 3를 Edição. Reino Unido: McGraw-Hill Book Co.; 1986. Fatigue of Metals; p. 375-376. 